\title{
Analysis of the Active Earth Pressure Under Different Displacement Modes of the Rigid Retaining Wall
}

\author{
Fuguang ZHU ${ }^{1, a}$, Hanyang LIU1, Lian FAN ${ }^{1}$, Xiaodong LIU ${ }^{1}$ and Zhe ZHOU² \\ ${ }^{1}$ Hubei electric power survey \& design institute, Wuhan 430040, China \\ ${ }^{2}$ Institute of Rock and Soil Mechanics, Chinese Academy of Sciences, Wuhan 430071, China \\ a331584689@qq.com
}

\begin{abstract}
Keywords: Active Earth Pressure, Displacement Mode, Rigid Retaining Wall.
Abstract. Earth pressure is the main load acting on the foundation pit support system, which is the result of the interaction between soil and retaining structure. Based on the different displacement modes of the retaining wall under the active earth pressure condition, the finite element method is used to analyze the characteristics and variation of the active earth pressure distribution of the retaining wall in various displacement modes. The distribution of earth pressure is essentially linear until the soil is destroyed under T mode, the upper part soil reach the active earth pressure state first under RBT mode and the lower part soil reach the active earth pressure state first. In RBT and RTT modes, when $n$ is large, the state of the earth pressure distribution at each stage is close to the state when the retaining wall translates.
\end{abstract}

\section{Introduction}

The environmental effects of foundation pit engineering must be related to the problem of earth pressure[1-3]. Earth pressure is the main load acting on the foundation pit support system, which is the result of the interaction between soil and retaining structure[4-6]. The relationship between the foundation pressure and the deformation of the soil and the calculation problem have been widely concerned by the researchers. Coulomb and Rankine earth pressure theory are widely used because of the simplicity of calculation and the concept of mechanics. It is assumed that the retaining structure is a rigid body, and the soil is an ideal rigid plastic body, subject to the Mohr-Coulomb criterion. According to the classical earth pressure theory, the earth pressure value of the linear distribution can be obtained under the limit equilibrium state. However, in classical earth pressure theory, the soil deformation is not considered, so the result is not accurate[7-9].

Based on the different displacement modes of the retaining wall under the active earth pressure condition, the finite element method is used to analyze the characteristics and variation of the active earth pressure distribution of the retaining wall in various displacement modes, to further improving the calculation model of earth pressure of foundation pit support structure.

\section{Displacement Mode Under Active Earth Pressure}

By giving a quantitative design mode of the retaining wall deviating from the soil, the active earth pressure of the soil can be obtained. In order to analyze the influence of the displacement mode of the retaining wall on the size and distribution of the earth pressure, the active state adopts three kinds of displacement methods, namely, T mode, RBT mode and RTT mode. The ratio of the vertical distance, between the center of the rotor and the wall toe, to the height of the wall is $\mathrm{n}$, and when $n=0$, the rotation point is located at the wall toe, the RBT mode and the RTT mode are converted into the RB mode and the RT mode of the non-combined displacement mode. Therefore, RB mode and RT mode are special cases of RBT mode and RTT mode. When the wall is rotated, the $s$ refers to the maximum displacement of the wall $S_{\max }$, when the RBT mode occurs, $s$ for the wall top displacement; When RTT mode occurs, $s$ for the toe displacement. 

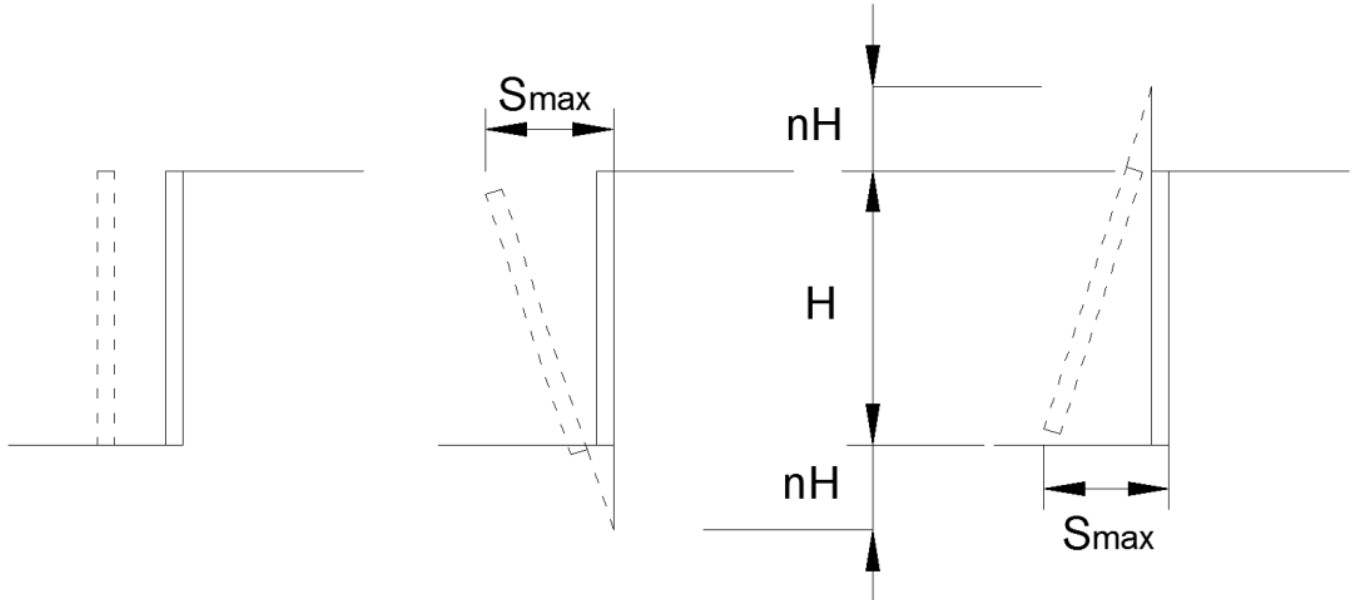

Figure 1 The retaining wall T, RBT, RTT displacement mode under active condition

\section{Finite Element Analysis Model}

Two-dimensional geometric model of earth pressure calculation in different displacement modes of rigid retaining wall are established. Rigid retaining wall $10 \mathrm{~m}$ high, to meet the general requirements of deep foundation pit, wall width is $30 \mathrm{~m}$. The soil adopts four-node solid element, the retaining wall adopts beam element, and the finite element grid size is $0.5 \mathrm{~m}$. An X-direction displacement load is applied to the wall. The contact surface is built between the retaining wall and the soil to simulate the interaction, between soil and structure, mainly friction effect.

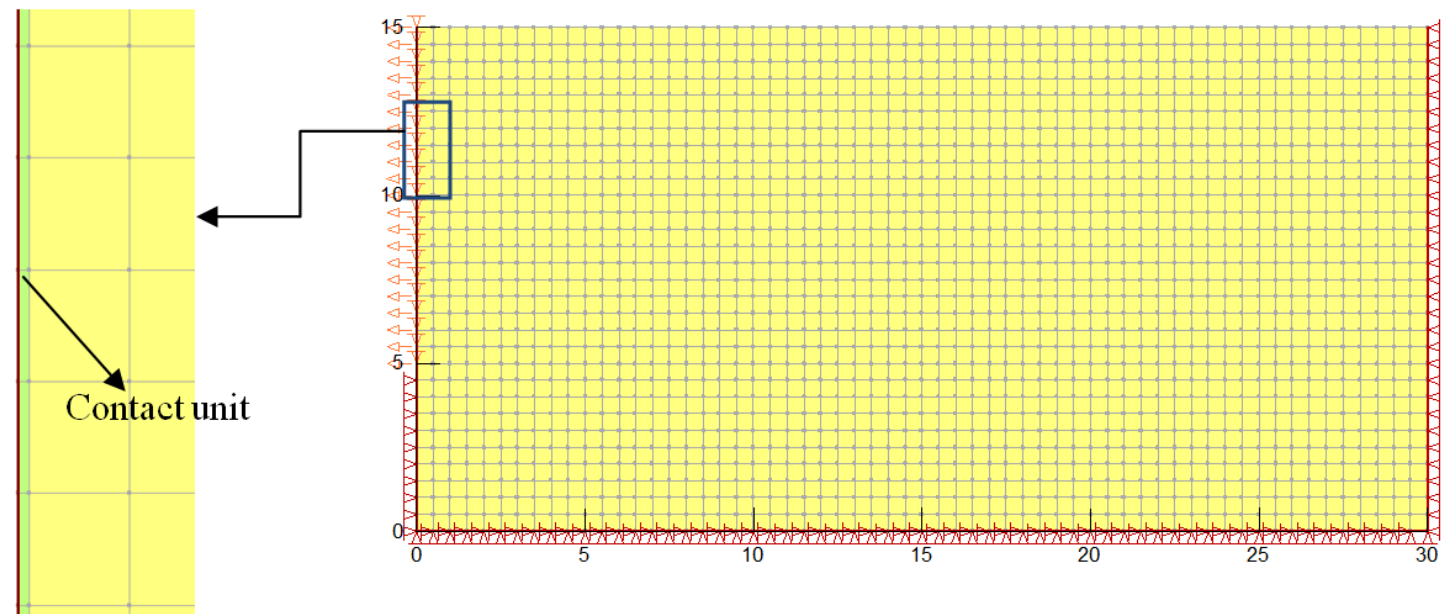

Figure 2 The finite element model

The Mohr-Coulomb model is used in the finite element analysis of earth pressure. The backfill is isotropic non-cohesive soil, and soil basic parameters as follows:

Table 1 Basic parameters of soil

\begin{tabular}{ccccc}
\hline Elastic Modulus/MPa & Density $/ \mathrm{kN} / \mathrm{m}^{3}$ & Cohesion $/ \mathrm{kPa}$ & $\begin{array}{c}\text { Internal friction } \\
\text { angle } /{ }^{\circ}\end{array}$ & $\begin{array}{c}\text { Poisson's } \\
\text { ratio }\end{array}$ \\
\hline 18 & 15.6 & 0 & 35 & 0.3 \\
\hline
\end{tabular}

\section{Analysis of Active Earth Pressure in Various Displacement Modes of Retaining Wall}

Uniform translation (T mode). When the wall is translated, the distribution of earth pressure at the different displacement stages is shown in Fig. 3. Due to the displacement of the retaining wall deviating from the soil, the wall pressure decreases gradually from the beginning of the static earth 
pressure and eventually decreases to the ultimate active earth pressure. At different displacement stages, the distribution of earth pressure is essentially linear until the soil is destroyed. However, due to the constraint of the lower boundary and the left boundary of the model, the calculation results of the earth pressure and the distribution of the earth pressure at the bottom of the retaining wall are different.

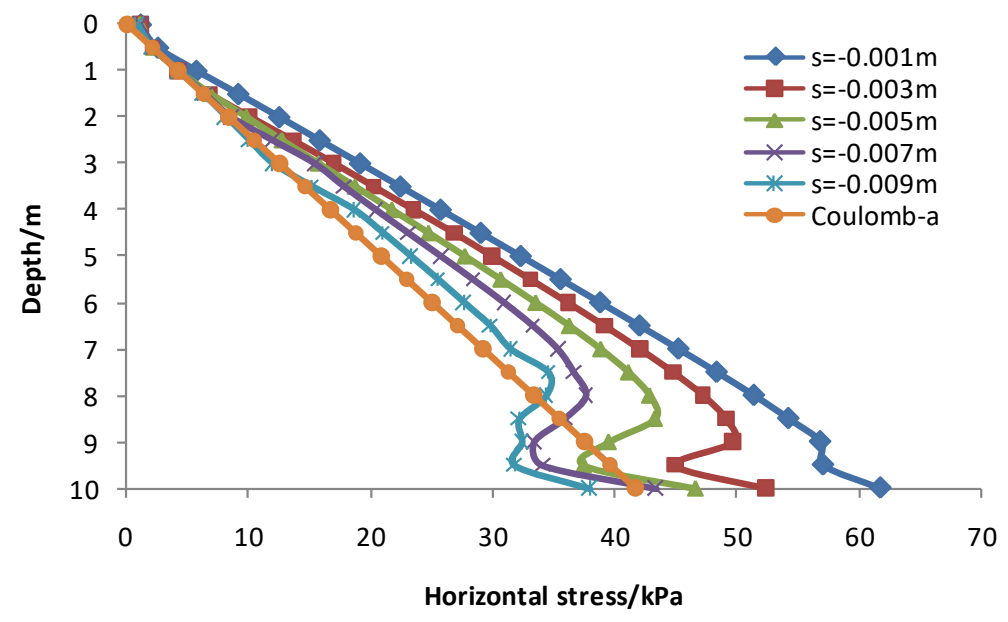

Figure 3 Active earth pressure distribution curve with different displacement in $\mathbf{T}$ mode

Rotate around the bottom (RBT mode). When the wall is rotated around the bottom, the horizontal earth pressure distribution of the wall is shown in the Fig. 4. Due to the displacement of the retaining wall deviating from the soil, the backfill earth pressure gradually decreases from the beginning of the static earth pressure. When $n=0 \sim 1$, the reduction rate of the earth pressure on the upper part of the retaining wall is obviously larger than that of the lower, and first to reach the active earth pressure state. This is because the displacement of the upper part of the retaining wall is greater than the lower displacement. At the bottom of the retaining wall, the change of the earth pressure is very small due to the small displacement of the retaining wall, and the active earth pressure state cannot be reached. Therefore, in different displacement stages, the distribution of earth pressure is obviously nonlinear; When $n>1$, the reduction rate of the earth pressure on the lower part of the retaining wall begin to approach the upper part, while the upper part still reach the active earth pressure state first. When the wall displacement is large, the bottom of the retaining wall can be close to the active earth pressure state, and at different displacement stages, the distribution of earth pressure is non-linear, but not very significant. When $n$ is larger, the state of the earth pressure distribution at each stage is close to the state when the retaining wall translates.

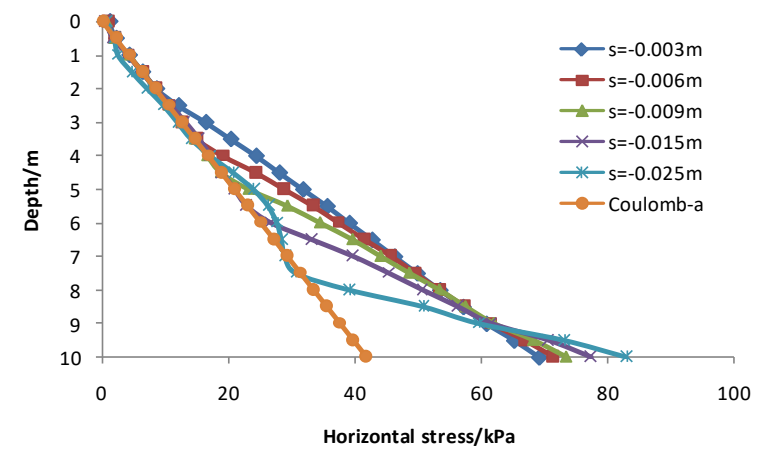

(a) $n=0$

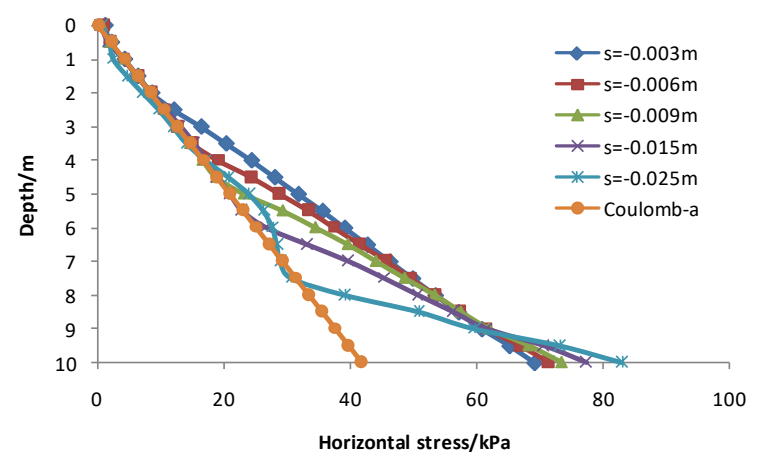

(b) $\mathrm{n}=0.5$ 


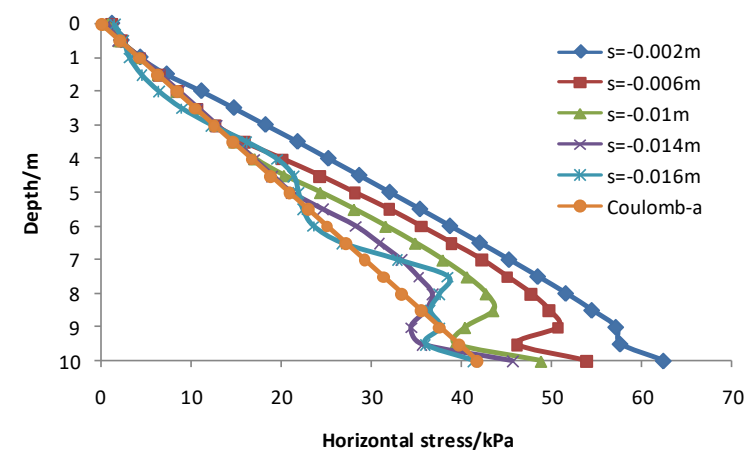

(c) $n=1$

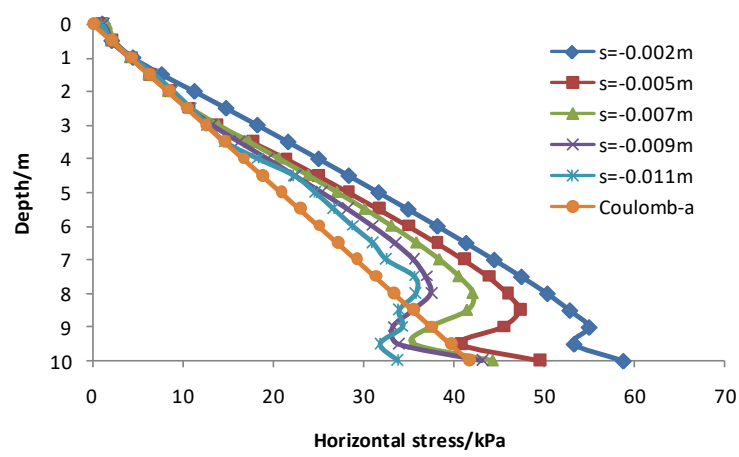

(d) $n=4.0$

Figure 4 Active earth pressure distribution curve with different displacement in RBT mode

Rotate around the top (RTT mode). When the wall is rotated around the wall, the horizontal earth pressure distribution back the wall is shown in the Fig. 5. Due to the displacement of the retaining wall deviating from the soil, the earth pressure back the wall gradually decreases from the beginning of the static earth pressure. When the $n$ is small, the reduction rate of the earth pressure on lower part is fast, and eventually the active earth pressure state is reached. This is because of the larger displacement of the lower part of the retaining wall, and at the top of the retaining wall, due to the small displacement of the retaining wall, the restraint effect of the retaining wall causes the backfill to produce soil arching effect, thus the earth pressure is greater than the static earth pressure. Therefore, in different displacement stages, the distribution of earth pressure is obviously nonlinear. When $\mathrm{n}>2$, the rate of change of earth pressure at different depths is basically the same, and the soil will reach the active earth pressure state meantime. The distribution of earth pressure is essentially linear until the soil is destroyed. At this time, the earth pressure distribution of backfill is similar to that of the retaining wall translates (T mode).

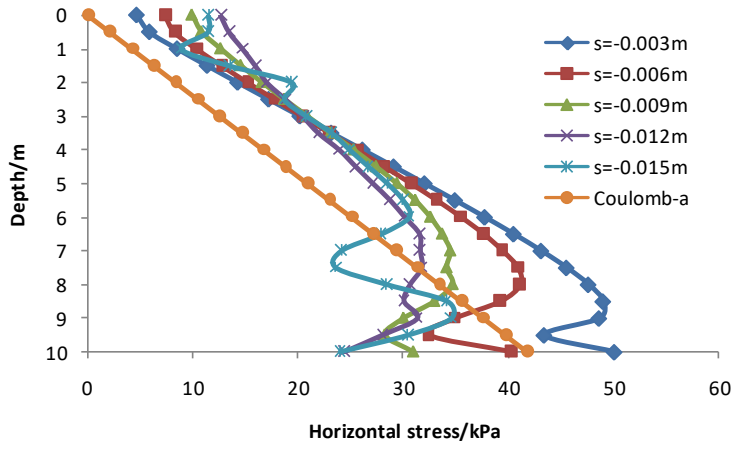

(a) $n=0$

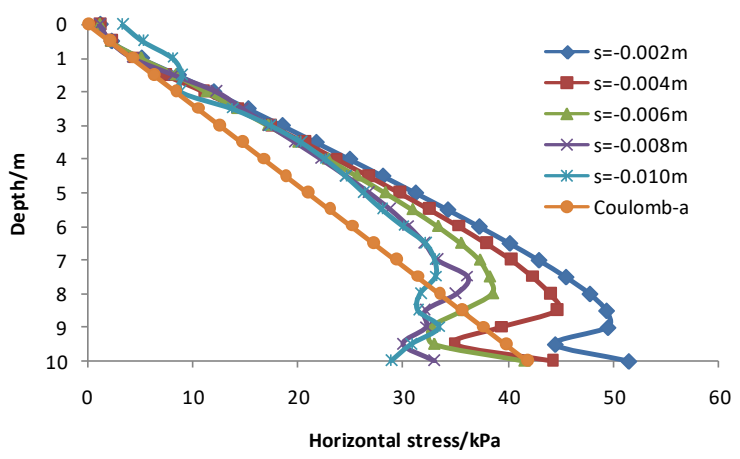

(c) $n=2.0$

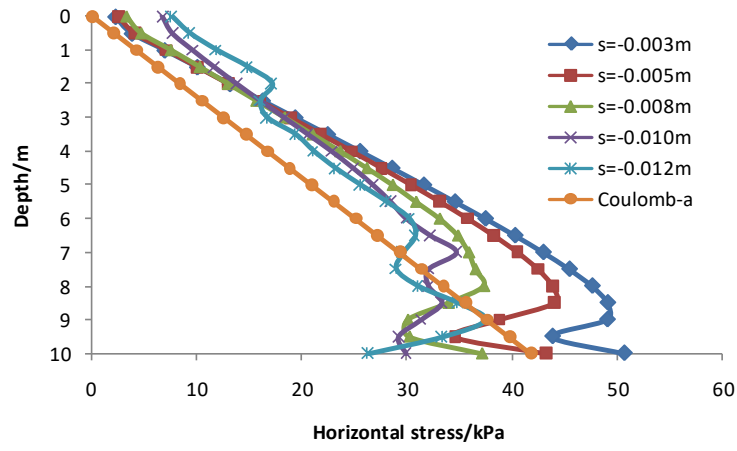

(b) $n=0.5$

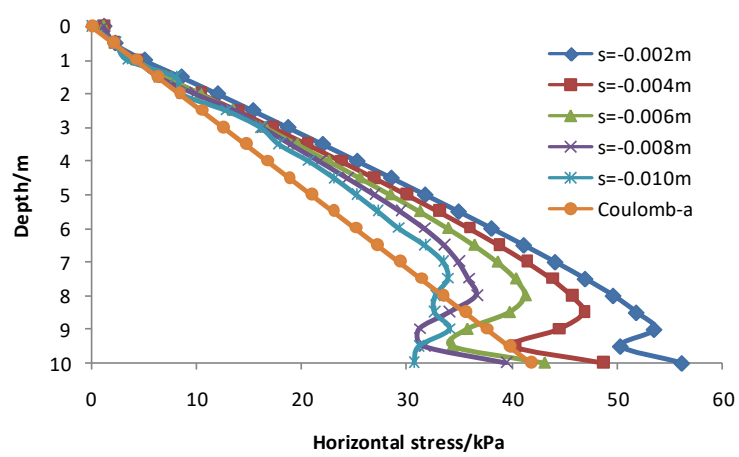

(d) $n=5.0$

Figure 5 Active earth pressure distribution curve with different displacement in RTT mode 


\section{Summary}

The distribution of earth pressure is essentially linear until the soil is destroyed under T mode, the upper part soil reach the active earth pressure state first under RBT mode and the lower part soil reach the active earth pressure state first. In RBT and RTT modes, when $n$ is large, the state of the earth pressure distribution at each stage is close to the state when the retaining wall translates (T mode).

\section{References}

[1] Gnanapragasam, Nirmala. Active earth pressure in cohesive soils with an inclined ground surfac. Canadian Geotechnical Journal 37.1(2001):171-177.

[2] Chen, Zuyu, and S. Li. Evaluation of active earth pressure by the generalized method of slice. Canadian Geotechnical Journal 35.4(1998):591-599.

[3] Soubra, Abdul Hamid. Static and seismic passive earth pressure coefficients on rigid retain. Canadian Geotechnical Journal 37.2(2011):463-478.

[4] Chen, J., and M. X. Peng. Slip-line solution to active earth pressure on retaining walls. Geotechnique 63.12(2013):1008-1019.

[5] Ghanbari, Ali, and M. Taheri. An analytical method for calculating active earth pressure in reinforced retaining walls subject to a line surcharge. Geotextiles \& Geomembranes 34.10(2012):1-10.

[6] Khosravi, Mohammad Hossein, T. Pipatpongsa, and J. Takemura. Theoretical analysis of earth pressure against rigid retaining walls under translation mode. Soils \& Foundations 56.4(2016):664-675.

[7] Goel, Shubhra, and N. R. Patra. Effect of Arching on Active Earth Pressure for Rigid Retaining Walls Considering Translation Mode. International Journal of Geomechanics 8.2(2008):123-133.

[8] Ying, Hong Wei, et al. Experimental analysis of passive earth pressure against rigid retaining wall under translation mode for finite soils. Chinese Journal of Geotechnical Engineering (2016).

[9] Rao, P. P., et al. Simplified Method for Calculating Active Earth Pressure on Rigid Retaining Walls Considering Arching Effect in Retained Cohesive Soil under Translation Mode. International Journal of Geomechanics (2015). 